\title{
Fast chromatographic determination of polycyclic aromatic hydrocarbons in aerosol samples from sugar cane burning
}

\author{
Ana F. L. Godoi ${ }^{1 *}$, Khaiwal Ravindra ${ }^{1}$, Ricardo H. M. Godoi ${ }^{1}$, Sandro J. Andrade ${ }^{2}$, Mary \\ Santiago-Silva ${ }^{2}$, Luc Van Vaeck ${ }^{1}$, René Van Grieken ${ }^{1}$ \\ ${ }^{1}$ Micro- and Trace Analysis Center, Department of Chemistry, University of Antwerp (UIA), \\ Universiteitsplein 1, B-2610 Antwerp, Belgium \\ ${ }^{2}$ Analytical Chemistry Department, Chemistry Institute, São Paulo State University (UNESP), Rua \\ Professor Francisco Degni s/n, PO Box 355, 14801-970, Araraquara - SP, Brazil
}

\begin{abstract}
Sugar cane burning in Brazil causes remarkable amounts of organic compounds to be emitted amongst which the polycyclic aromatic hydrocarbons (PAHs) represent serious health hazards. Therefore, twenty-four hour aerosol samples $(<10 \mu \mathrm{m}$ aerodynamic diameter $)$ were collected in Araraquara city (São Paulo state) during the harvest season using a Hi-Vol sampler. PAHs were recovered using an Accelerated Solvent Extractor and analyzed by low pressure-gas chromatography-ion trap mass spectrometry (LP-GC-ITMS). The fully automated extraction process was performed in less than 25 min with a solvent consumption of approximately $20 \mathrm{~mL}$. The use of a deactivated $0.6 \mathrm{~m} \times 0.10 \mathrm{~mm}$ ID restrictor coupled to a $10 \mathrm{~m}$ wide-bore analytical column allowed most of the 16 PAHs in EPA's priority list to be identified and quantified in only 13 min. Concentrations of PAHs in Araraquara aerosols ranged between $0.5 \mathrm{ng} \mathrm{m}^{-3}$ and $8.6 \mathrm{ng} \mathrm{m}^{-3}$.
\end{abstract}

Keywords: PAHs, fast analysis, sugar cane burning, LP-GC-ITMS

(*) Fax number: +32 3 8202376; e-mail address: agodoi@uia.ua.ac.be 


\section{Introduction}

Brazil owns $25 \%$ of the world's cultivated area for sugar cane and therefore is one of the major producers. Although used since 1917 as automotive fuel, ethanol had its production greatly expanded after 1970, when the Brazilian Government developed the PROÁLCOOL program. The extensive sugar cane culture accessible in the country encouraged the production of a relatively clean fuel using a renewable energy source at low cost. Nowadays the cultivated area comprehends 3.12 million hectares, which produced 11 billion liters of ethanol and 142.8 million tons of sugar in the last 2002 season [1,2]. In particular, the Southeast region, mainly the São Paulo state, is responsible for $80 \%$ of the national production and involves approximately 400,000 workers.

At harvesting season, from May to November, the crops are burnt to make the process of manual harvesting easier, by protecting the rural workers from the sharp leaves, insects and poisonous snakes, and also to increase the sugar content by weight due to water evaporation [3]. In natural and anthropogenic fires, incomplete combustion results in the formation of compounds such as carbon monoxide, ammonia, methane and higher hydrocarbons [4]. Amongst the organic emissions, polycyclic aromatic hydrocarbons (PAHs) are the most feared ones due to their carcinogenic and/or mutagenic properties [5,6]. Recently their endocrine disruption action has been reported [7]. Sixteen PAHs are included in the priority pollutants list of the US Environmental Protection Agency (EPA) [8].

The pyrolysis of the organic matter under high temperatures and consequent recombination of acetylene units results in condensed polyaromatic molecules [9], present in both the gas and particulate phases. Low molecular weight PAHs are found predominantly in the gas phase, while those with four or more rings are found mainly in the particle phase. Van Vaeck et al. [10] have found that about $80 \%$ of the atmospheric inventory of particulate PAHs is associated with particles below $1 \mu \mathrm{m}$. Miguel and Friedlander [11] have reported that around $75 \%$ of benzo[a]pyrene $(\mathrm{B}[\mathrm{a}] \mathrm{P})$ is associated with particles smaller than $0.26 \mu \mathrm{m}$, that may deposit into the alveoli causing lung diseases such as asthma or emphysema, even when low concentrations are present. The prevalent presence of PAHs in the respirable fraction of submicrometer aerosol particles generates a special interest from the health point of view [12] and constitutes a real hazard although the extent of such contributions remains almost unknown. The characterization of individual particle composition using microanalysis methods is thus of great relevance [13]. In the Southeast of Brazil, regional air pollution caused by sugar cane burning has become a serious problem with potential effects on human health and the global environment. Arbex et al. [14] observed a strong correlation between the amount of smoke particles deposited in a medium city in the state of São Paulo and the 
number of persons who needed inhalation therapy in a local hospital, indicating that sugar cane burning may cause deleterious health effects in the exposed population. Zamperlini et al. [15] reported the identification of 38 compounds originating from sugar cane soot: the sixteen PAHs from EPA's priority pollutants list, some alkyl PAHs and tiophen derivatives. However, up to now there is no specific information concerning the chemical composition of the aerosol during the sugar cane burning season and the subsequent effects on the exposed population in the region

For a long time the accurate identification and quantification of such trace pollutants has been a challenge for environmental science. High performance liquid chromatography (HPLC) is usually coupled to diode-array, fluorescence or UV detectors, but chromatographic resolution is limited. In this respect, capillary gas chromatography (GC) performs better but the extreme complexity of aerosol samples practically requires coupling to a mass spectrometer (MS) for reliable identification [16]. Nowadays GC-MS comprises one of the standard methods for the determination of PAHs in ambient air [17]. However, GC performed with conventional capillary columns $(30 \mathrm{~m} \times 0.25 \mathrm{~mm})$ results in long analysis times. In addition, the classical extraction methods, such as Soxhlet for instance, are extremely laborious and time-consuming. This was the motivation to apply a new GC-ITMS technique [18] combined with accelerated solvent extraction (ASE) in order to detect and quantify polycyclic aromatic hydrocarbons in aerosol samples in a fast, accurate and reliable approach.

\section{Experimental}

\section{Solvents and standards}

All reagents used were of analytical reagent grade. Dichloromethane (DCM), methanol $(\mathrm{MeOH})$ and isooctane were purchased from Merck (Darmstadt, Germany). Pure PAHs (acenaphthene, acenaphthylene, anthracene, benzo[a]anthracene, benzo[b]fluoranthene, benzo[k]fluoranthene, benzo[g,h,i]perylene, benzo[a]pyrene, benzo[e]pyrene, chrysene, dibenzo[a,h]anthracene, fluoranthene, fluorine, indeno[1,2,3-c,d]pyrene, naphthalene, perylene, phenanthrene, pyrene) as well as a standard mixture (PAH-Mix 45) and a mixture of perdeuterated PAHs (PAH-Mix 31: acenaphthene-D10, chrysene-D12, naphthalene-D8, perylene-D12, phenanthrene-D10) were purchased from Dr. Ehrenstorfer (Augsburg, Germany).

\section{Sampling and site characterization}

Located at latitude $21^{\circ} 48^{\prime} 11^{\prime \prime} \mathrm{S}$ and longitude $48^{\circ} 08^{\prime} 25^{\prime}, \mathrm{W}$ and with a population of about 200,000 inhabitants, Araraquara is in the center of the so-called "sugar cane belt", an interior region of the state of São Paulo responsible for most of the sugar cane business in Brazil. 
Particulate matter in the size range $<10 \mu \mathrm{m}\left(\mathrm{PM}_{10}\right)$ was collected for twenty-four hours during ten days in August 2002, corresponding to the winter harvest season. A high-volume sampler (Hi-Vol $\mathrm{PM}_{10}$, Energética, Brazil) operating with an average flow rate of $1.13 \mathrm{~m}^{3} \mathrm{~min}^{-1}$ was placed at $4 \mathrm{~m}$ height at a sampling site located in the Institute of Chemistry of the São Paulo State University, in a suburban area. The closest sugar cane crop is at a distance of approximately $5 \mathrm{~km}$. Based on the 30-day air mass back trajectories, obtained from the Hybrid Single-Particle Langrangian Integrated Trajectory model (HYSPLIT), the sampled air masses at Araraquara were coming from the Atlantic Ocean to the center of Brazil [19].

Atmospheric particulate samples were collected using glass fiber filters (Pallflex Products Corporation, $20 \mathrm{~cm} \times 25 \mathrm{~cm}$ surface), that were pre-heated at $400{ }^{\circ} \mathrm{C}$ during $24 \mathrm{~h}$ before use to lower their water and organic matter blank values. After cooling, filters were weighed and stored in solvent-rinsed aluminum foil until use.

The concentrations of the collected total suspended particulate (TSP), the volume of air sampled, and the temperature for each day are given in Table I.

\section{Sample extraction and GC-MS analysis}

The entire filter was cut into 6 parts and one (average weight $0.45 \mathrm{~g}$ ) was loaded into a $5 \mathrm{~mL}$ extraction cell. The extractions were performed using a pressure of $160 \mathrm{bar}$ at a temperature of 100 ${ }^{\circ} \mathrm{C}$. The solvent consisted of 4:1 DCM:MeOH. The cycle times were 5 min heat-up and 5 min static extraction. The flush volume was $150 \%$. The full cycle was repeated 3 times, and after extraction the instrument was purged three times with nitrogen (Air Liquide, Liège, Belgium) for $60 \mathrm{~s}$. Prerinsed $40 \mathrm{~mL}$ screw-cap I-chem vials were used to collect the extracts (approximately $20 \mathrm{~mL}$ ), that were afterwards concentrated under $\mathrm{N}_{2}$ until dryness at room temperature and re-dissolved in 500 $\mu \mathrm{L}$ isooctane. A blank filter section was handled using exactly the same procedures as those used for field samples.

Low pressure GC-ITMS analyses were performed on a Varian 3800 GC (Walnut Creek, CA, USA) instrument equipped with a CP-Sil 8 Rapid $\mathrm{MS}^{\circledR}$ column $\left(10 \mathrm{~m}\right.$ x $0.53 \mathrm{~mm}$ I.D.; $\mathrm{d}_{\mathrm{f}}=1 \mu \mathrm{m}$, Varian-Chrompack) attached to a uncoated restriction column of $60 \mathrm{~cm}$ x $100 \mu \mathrm{m}$ I.D. (VarianChrompack) by a single ferrule column connector and a vespel ferrule 0.53-0.25 mm I.D. The column was kept at $40{ }^{\circ} \mathrm{C}$ during 1 min before temperature programming to 120 and $260{ }^{\circ} \mathrm{C}$ at a rate of 40 and $15{ }^{\circ} \mathrm{C} \min ^{-1}$, respectively. The final temperature was kept for 1.17 min to complete elution. Helium (Air Liquide, Liège, Belgium) was used as carrier gas at a constant flow rate of 1.5 $\mathrm{mL} \min ^{-1}$. Splitless injections $(1 \mu \mathrm{L})$ were carried out through a universal injector (Varian 1079) operating at $290{ }^{\circ} \mathrm{C}$, and the samples were introduced using an 8200 Varian auto-sampler. A Varian Saturn 2000 ion trap MS was used as a detection system, keeping the transfer line temperature at 
$230{ }^{\circ} \mathrm{C}$. The full optimization of the analytical methodology for PAHs determination by LP-GCITMS and additional details on its validation in comparison to conventional GC-ITMS is described elsewhere [18].

In this work the 16 PAHs listed by the US EPA as priority pollutants plus benzo[e]pyrene were analyzed. The target compounds were identified by GC retention times, comparison with authentic standards, and from their recorded mass spectra by comparison with the NIST library (100,000 compounds). Perdeuterated PAHs were used as internal standards to quantify the individual analytes by the LP-GC-ITMS analysis.

\section{Results and discussion}

\section{Accelerated solvent extraction (ASE)}

According to Richter et al. [20], the extraction efficiency using ASE is comparable to that obtained by Soxhlet extraction, encouraging us to apply such procedure to our samples. Using optimized conditions described by Alexandrou et al. [21], the fully automated ASE extraction process was performed in less than $15 \mathrm{~min}$, whereas Soxhlet extraction required 16 and $20 \mathrm{~h}$ according to Caricchia et al. [22] and Kavouras et al. [23], respectively. Furthermore a total solvent consumption with ASE could be reduced to approximately $20 \mathrm{~mL}$. Hence ASE provided a very fast procedure with a minimum consumption of toxic solvents and environmental burden, nowadays two crucial parameters in the choice of the extraction technique.

\section{LP-GC-ITMS analysis}

Conventional PAHs chromatographic separations are performed generally within 30-40 min in order to elute all compounds. The temperature-programming rate needs to be low enough for the complete separation of PAHs and results in a long chromatographic experiment, preferentially in a thin film column with low capacity. The low-pressure GC is then an attractive alternative to shorten the analysis time. Furthermore, the use of wide bore thick film columns operating under vacuum conditions allows the capacity of the system to be increased substantially.

Using the LP-GC-ITMS approach, the best separation was achieved with a CP-Sil 8 column and very fast program rates (i.e. 15 and $40{ }^{\circ} \mathrm{C} \mathrm{min}^{-1}$ ). The total elution took less than 13 min in spite of the low initial temperature $\left(40{ }^{\circ} \mathrm{C}\right)$. Of particular interest is the decrease of the retention time for individual PAHs by a factor of 3-4, without loss of the baseline separation (except for benzo[b]- and benzo[k]fluoranthene), and the improvement of the detection limits, as already reported by Ravindra et al. [18]. The mass spectra of target compounds agreed well with those from authentic standards, in that fit-factors were similar (see Figure 1). Additionally, the retention time reproducibility between samples and standards was enough to ensure the identification of the target 
analytes. Moreover, the use of the ITMS permitted the entire mass spectra to be obtained with a sensitivity that exceeded that of quadrupole/single ion monitoring [24].

Finally, the outlined advantages of fast analysis and lower gas-consumption are decisive parameters to be taken into account for routine monitoring, not only at the industrial scale, but also in a research laboratory.

\section{Atmospheric particulate matter}

Particulate PAHs concentrations are summarized in Table II. The average value for each compound, with the minimum and maximum values and the total PAHs concentrations (sum of the 18 compounds) are reported for the 10 days sampling. The typical reproducibility of instrumental analysis is $10-15 \%$. The values were corrected for volatilization losses during the evaporation step under $\mathrm{N}_{2}$ [22]. The estimated recovery yield ranged from $78 \pm 5 \%$ for naphthalene to $85 \pm 3 \%$ for benzo[g,h,i]perylene. According to Caricchia et al. [23], losses of PAHs from particulate collected on filters are more significant for the compounds containing less than five rings when the sampling time exceeds $24 \mathrm{~h}$. Therefore, the concentrations reported in Table II are a good estimation of the environmental levels.

Concentrations of individual compounds are in a range of up to $18 \mathrm{ng} \mathrm{m}^{-3}$. The total PAHs levels are between 13 and $94 \mathrm{ng} \mathrm{m}^{-3}$. These values are close to those observed in Naples $(2-130 \mathrm{ng}$ $\left.\mathrm{m}^{-3}\right)$ [23] and exceed those measured in Santiago de Chile $\left(0.68-11.14 \mathrm{ng} \mathrm{m}^{-3}\right)$ [24]. The average concentration for total PAHs of $49 \mathrm{ng} \mathrm{m}^{-3}$ measured in Araraquara is also higher than that observed in Seoul (26.3 $\left.\mathrm{ng} \mathrm{m}^{-3}\right)$ [26].

Because PAHs are generally considered as typical products of incomplete combustion of organic matter, the increased concentrations in Araraquara are readily associated to the intense sugar cane burning which takes place at this time of the year in the surrounding area. Indeed, Azevedo et al. [27] also observed high average concentrations in Campos dos Goytacazes (up to $122 \mathrm{ng} \mathrm{m}^{-3}$ ), another city surrounded by sugar cane plantations. Our average concentration for total PAHs (samples collected in August) is lower, probably due to the sampling in atypical winter conditions with temperatures reaching $30{ }^{\circ} \mathrm{C}$. The latter could increase the gas particle distribution of PAHs compounds. Also, Azevedo et al. [27] showed a seasonal distribution with high PAHs concentrations in July with a strong decrease until the end of the crop season (September). Of course, variables such as climate, air masses, other anthropogenic contributions and unpredictable crop burnings, characteristic of both cities, should also to be taken in to account.

The average $\mathrm{B}[\mathrm{a}] \mathrm{P}$ concentration $\left(1.9 \mathrm{ng} \mathrm{m}^{-3}\right)$ measured in Araraquara is of special interest due to its high carcinogenic property, being higher than those measured in large cities in developed countries such as London [28]. According to Simoneit [9] the major PAHs emitted from Gramineae 
species burning are phenanthrene, fluoranthene and pyrene, and the minor anthracene and benzo[a]anthracene. The concentrations of these compounds detected in our work are compatible with this observation, suggesting that the PAHs emissions are indeed produced by the sugar cane burning.

The total suspended particle matter (TSP) ranged from $76 \mu \mathrm{g} \mathrm{m}^{-3}$ to $182 \mu \mathrm{g} \mathrm{m}^{-3}$, and was below the Brazilian Regulation limits $\left(150-240 \mu \mathrm{g} \mathrm{m} \mathrm{m}^{-3}-24 \mathrm{~h}\right.$ air quality standard; Resolution CONAMA no. 03). However, the average $\left(103 \mu \mathrm{g} \mathrm{m}^{-3}\right)$ is above the annual geometric average of 80 $\mu \mathrm{g} \mathrm{m}^{-3}$, probably due to intense crop burning processes. It can explain the increase of respiratory problems observed in the population during the winter season as reported by Arbex et al. [14], mainly in dry days when the contributions of the large amount of agricultural fires to the emission of particulate matter are maximal, as demonstrated by Godoi et al. [13]. Indeed, the World Health Organization (WHO) advises that even at low levels of particulate matter (less than $100 \mu \mathrm{g} \mathrm{m}^{-3}$ ) short-term exposure is associated with health effects. Evidence is also emerging that long-term exposure to low concentrations is associated with mortality and other chronic effects, such as increased rates of bronchitis and reduced lung function [29]. 


\section{References}

[1] http://www.canaweb.com.br

[2] http://www.cna.org.br

[3] G. C. M. Zamperlini, M. R. S. Silva, W. Vilegas, J. Chromatogr. A 2000, 889, 281.

[4] R. Delmas, J. P. Lacaux, D. Brocard, Environ. Monit. Assess. 1995, 38, 181.

[5] J. Dejmek, I. Solanský, I. Beneš, J. Leniček, R. J. Šrám, Environ. Health Perspect. 2000, 108, 1159.

[6] B. Binková, M. Černá, A. Pastorková, R. Jelínek, I. Beneš, J. Novák, R. J. Šrám, Mutat. Res. 2003, 525, 43 .

[7] W. Z. Wu, J. X. Wang, G. F. Zhao, You L, J. Environ. Sci. Heal. A 2002, 37, 579.

[8] "Evaluation and Estimation of Potencial Carcinogenic Risks of Polynuclear Aromatic Hydrocarbons", US Environmental Protection Agency, Carcinogen Assessment Group, Cincinatti, 1988.

[9] B. R. T. Simoneit Appl. Geochem. 2002, 17, 129-162.

[10] L. Van Vaeck, G. Broddin, K. Van Cauwenberghe, Environ. Sci. Technol. 1979, 13, 1494.

[11] A. Miguel, S. K. Friedlander, Atmos. Environ. 1978, 12, 2407.

[12] Ravindra, A. K. Mittal, R. Van Grieken, Rev. Environ. Health, 2001, 16, 169.

[13] R. H. M. Godoi, A. F. L. Godoi, A. Worobiec, S. J. Andrade, M. Santiago-Silva, J. de Hoog, R. Van Grieken, Mikrochim. Acta, submitted.

[14] M. A. Arbex, G. M. Böhm, P. H. N. Saldiva, G. M. S. Conceição, A. C. Pope, A. L. F. Braga, J. Air \& Waste Manage. Assoc. 2000, 50, 1745-1749.

[15] G. C. M. Zamperlini, M. R. S. Silva, W. Vilegas, Chromatographia 1997, 46, 655.

[16] F. J. Santos, M. T. Galceran, Trend. Anal. Chem. 2002, 21, 672.

[17] "Determination of Polycyclic Aromatic Hydrocarbons (PAHs) in Ambient Air Using Gas Chromatography/Mass Spectrometry (GC/MS)", Compendium Method TO-13A, US Environmental Protection Agency, Cincinnati, 1999.

[18] K. Ravindra, A. F. L. Godoi, R. Van Grieken, J. Chromatogr. A, submitted for publication.

[19] htpp://arl.noaa.gov/ss/models/hysplit.html

[20] B. E. Richter, B. A. Jones, J. L. Ezzell, N. Porter, N. Avdalovic, C. Pohl, Anal. Chem. 1996, $68,1033$.

[21] N. Alexandrou, M. Smith, R. Park, K. Lumb, K. Brice, Intern. J. Environ. Anal. Chem. 2001, $81,257$.

[22] F-H. Chang, T. Lin, H-R. Chao, M-R. Chao, Intern. J. Environ. Anal. Chem. 2001, 80, 13.

[23] A. M. Caricchia, S. Chiavarini, M. Pezza, Atmos. Environ. 1999, 33, 3731. 
[23] I. G. Kavouras, J. Lawrence, P. Koutrakis, E. G. Stephanou, P. Oyola, Atmos. Environ. 1999, 33, 4977.

[24] G. Castello, T. C. Gerbino, J. Chromatogr. 1993, 642, 351.

[25] S. S. Park, Y. J. Kim, C. H. Kang, Atmos. Environ. 2002, 36, 2917.

[26] D. A. Azevedo, C. Y. M. Santos, F. R. Aquino Neto, Atmos. Environ. 2002, 36, 2383.

[27] C. J. Halsall, P. J. Coleman, B. J. Davis, V. Burnett, K. S. Waterhouse, P. Harding-Jones, K. D. Jones, Environ. Sci. Technol. 1994, 28, 2380.

[28] L. Koblinger, W. Hofmann, J. Aerosol Sci. 1990, 21, 661.

[29] http://www.who.int/environmental_information/Air/Guidelines/Chapter3.htm; Air quality guidelines, WHO, 1999. 
Table I - Total suspended particulate (TSP), volume of air collected, and ambient temperature for each sampling day in Araraquara

\begin{tabular}{ccccc}
\hline sample & date & Ambient & TSP & Volume \\
& & temperature $\left({ }^{\mathbf{C}} \mathbf{C}\right)$ & $\left(\boldsymbol{\mu g} \mathbf{~ m}^{-\mathbf{3}}\right)$ & sampled $\left(\mathbf{m}^{\mathbf{3}}\right)$ \\
\hline 1 & $05 / 08 / 02$ & $18-30$ & 78.8 & 1627 \\
2 & $06 / 08 / 02$ & $20-27$ & 76.3 & 1604 \\
3 & $07 / 08 / 02$ & $18-31$ & 78.5 & 1610 \\
4 & $08 / 08 / 02$ & $19-31$ & 108.5 & 1661 \\
5 & $09 / 08 / 02$ & $18-30$ & 115.3 & 1692 \\
6 & $10 / 08 / 02$ & $18-30$ & 97.3 & 1599 \\
7 & $12 / 08 / 02$ & $18-29$ & 103.6 & 1604 \\
8 & $13 / 08 / 02$ & $18-30$ & 104.8 & 1667 \\
9 & $14 / 08 / 02$ & $19-30$ & 181.8 & \\
\hline 10 & $15 / 08 / 02$ & $18-30$ & 89.0 & \\
\hline
\end{tabular}


Table II - PAHs concentrations $\left(\mathrm{ng} \mathrm{m}^{-3}\right)$ measured in $\mathrm{PM}_{10}$ aerosol samples collected in Araraquara

\begin{tabular}{|c|c|c|}
\hline Compound & Concentration range $\left(\mathrm{ng} \mathrm{m}^{-3}\right)$ & Average concentration $\left(\mathrm{ng} \mathrm{m}^{-3}\right)$ \\
\hline Naphthalene & $0.19-0.93$ & $0.42 \pm 0.27$ \\
\hline Acenaphthylene & $0.25-2.03$ & $0.95 \pm 0.62$ \\
\hline Acenaphthtene & $0.12-1.78$ & $0.70 \pm 0.56$ \\
\hline Fluorene & $0.11-0.91$ & $0.42 \pm 0.43$ \\
\hline Phenanthrene & $0.94-5.08$ & $2.9 \pm 1.2$ \\
\hline Anthracene & $0.11-0.51$ & $0.33 \pm 0.13$ \\
\hline Fluoranthene & $1.1-6.5$ & $3.3 \pm 1.6$ \\
\hline Pyrene & $0.57-6.03$ & $2.5 \pm 1.7$ \\
\hline Benzo[a]anthracene & $<0.74$ & - \\
\hline Chrysene & $1.7-13.8$ & $6.6 \pm 4.1$ \\
\hline Benzo[b+k]fluoranthene & $1.8-11.0$ & $5.6 \pm 3.3$ \\
\hline Benzo[a]pyrene & $<0.74-3.30$ & $1.9 \pm 1.1$ \\
\hline Benzo[e]pyrene & $1.0-4.6$ & $2.7 \pm 1.4$ \\
\hline Indeno[1,2,3-cd]pyrene & $<1.6-18.2$ & $8.7 \pm 5.6$ \\
\hline Dibenzo[a,h]anthracene & $<1.6$ & - \\
\hline Benzo[g,h,i]perylene & $2.5-13.8$ & $8.5 \pm 3.8$ \\
\hline Perylene & $1.2-5.6$ & $3.8 \pm 1.5$ \\
\hline Total & $13.4-94.0$ & $49.3 \pm 2.8$ \\
\hline
\end{tabular}




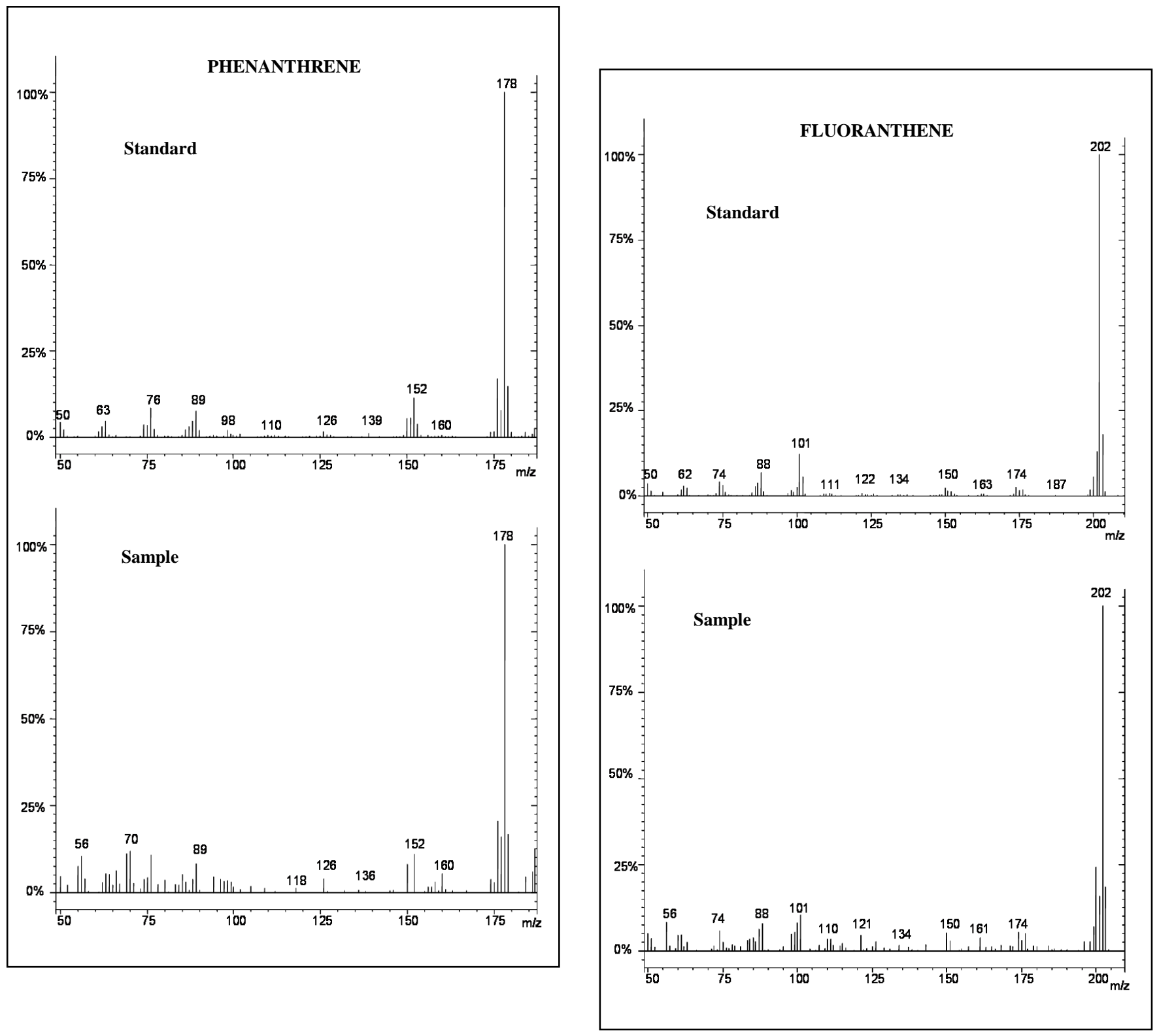

Figure 1 - Mass spectra of an authentic standard and a sample for phenanthrene and fluoranthene. 